\title{
Porque o medo importa: uma análise do papel do medo hobbesiano na política de defesa israelense
}

Because Fear Matters: An Analysis of the Role of Hobbesian Fear in the Israeli Defense Policy

\author{
Karina Stange Calandrin ${ }^{1}$
}

\section{RESUMO}

Como o medo em nível individual e social pode influenciar a política de defesa de um Estado? Com base em análises de Relações Internacionais e Psicologia Política, é proposta uma discussão sobre como a história de Israel e do povo judeu contribuiu para aumentar o medo hobbesiano (especificamente o medo da morte violenta) em nível social no país, tendo papel central na formulação da atual política de defesa israelense.

Palavras-chave: Política de defesa de Israel; Medo hobbesiano; Oriente Médio.

\begin{abstract}
How individual and social fear can influence a State defense policy? Based on International Relations and Political Psychology analysis, this article proposes a discussion about how the history of Israel and the Jewish people have contributed to increase the Hobbesian fear (specifically the fear of a violent death) on social level in the country, having a central role in the formulation of current Israeli defense policy.
\end{abstract}

Key-words: Israeli Defense Policy; Hobbesian Fear; Middle East

Introdução

O medo, mais especificamente o medo da morte, de acordo com Thomas Hobbes (1983), é o que determina e molda a vida humana. Ele permeia o estado de natureza. "Pior de tudo é o medo contínuo, e o perigo da morte violenta" (HOBBES, 1983. p. 78). É, ao mesmo tempo, a única origem da sociedade civil e os únicos meios fiáveis de sua preservação. Assim, o medo representa a principal causa da guerra e o principal meio para a paz; o medo é a base da existência do homem e sua única fuga possível (HOBBES, 1983).

\footnotetext{
1 Mestranda em Relações Internacionais do Programa de Pós-graduação San Tiago Dantas (Unesp/Unicamp/PUC-SP). São Paulo, Brasil.
} 
Dessa forma, o que se pretende entender nesse artigo é como o medo pode influenciar a política de defesa de um Estado, mais especificamente de Israel.

O papel desenvolvido na filosofia política por Hobbes foi amplamente aproveitado pela ciência. A suposição entre os estudiosos contemporâneos é que Hobbes considera o medo como a condição primária do homem, e a morte violenta, como a força mais poderosa na vida humana. Essa suposição predominante remonta à crítica de Rousseau a Hobbes. De acordo com Jean-Jacques Rousseau (2011), embora Hobbes negue que o homem é naturalmente social, o homem natural hobbesiano é caracterizado por qualidades produzidas pela sociedade e não pela natureza.

Além de possuir razão e previdência, o homem hobbesiano é impulsionado pelo orgulho e, acima de tudo, pelo medo de outros homens. Ele vive em constante medo por sua vida porque está cheio de paixões não naturais, incluindo o orgulho. Assim, em contraste com o homem autossuficiente natural de Rousseau, o homem hobbesiano carece de profundidade. Ele é político, e não psicológico, no sentido moderno que Rousseau dá a esse termo, porque o fato fundamental de sua vida não é algo radicalmente interno ou privado, mas sim a luta externa com outros homens, o que Hobbes chama de "estado de natureza". 0 medo da morte violenta é o estrato mais profundo em sua alma (HOBBES, 1983).

Já Rousseau (2011) nega a verdadeira solidão do homem hobbesiano ao afirmar que o medo da morte violenta é primário na visão de Hobbes. Como será visto, o relato de Hobbes do homem e de sua situação no mundo não começa com o estado de natureza, isto é, a relação do homem com os outros homens, mas sim com a sua relação com o mundo natural. Por essa razão, de acordo com Jon H. Blits (1989), o medo mais básico no relato de Hobbes não é o medo de outros homens, nem o temor de um deus ou dos espíritos, mas um medo mais profundo, mais radical, que precede e fundamenta esses dois temores prépolíticos.

Como consequência do medo, uma condição para a inimizade e a guerra universal do homem contra o homem decorre de suas limitações inerentes à cognição natural. Como será visto, iniciando-se com a crítica da sensação descrita por Hobbes, o medo hobbesiano é mais bem entendido como primal, o medo do desconhecido e do indeterminado. 
A análise do medo hobbesiano, por sua vez, será desenvolvida do ponto de vista da Psicologia Política. Mas o que é Psicologia Política? Por que é importante? O campo da Psicologia Política é mais do que a soma de duas partes, pois agrega valor aos estudos independentes da Ciência Política e da Psicologia. Combinando essas disciplinas, podemos obter um entendimento maior em tópicos que incluem o estudo da liderança política; o julgamento político e a tomada de decisão; a opinião pública e o comportamento eleitoral; o impacto da emoção sobre o comportamento; a interação entre os processos individuais e o comportamento do grupo; e a formação e a manutenção de valores dominantes na sociedade.

O que unifica a Psicologia Política e a torna distinta de outras formas de análise política é a busca de explicação, descrição e previsão no nível individual de análise, de acordo com Robert Jervis (1976). O nível individual de análise informa e afeta os tipos de perguntas que são feitas, os meios de prova que são procurados e as naturezas de inferências sobre a causalidade que são feitas por psicólogos políticos. Esse viés de atenção nem sempre é limitado à pessoa. Por vezes, ele incorpora o indivíduo, agindo em conjunto com outros indivíduos em configurações de grupo, mas, no entanto, ele privilegia a pessoa sobre organizações, burocracias, os níveis institucionais ou outros níveis de análise que diminuem a importância do indivíduo. De acordo com Rose McDermott (2004), a Psicologia Política fornece uma inclinação particularmente humanista sobre política, afirmando a importância dos processos psicológicos individuais para os resultados políticos.

Neste artigo pretendemos realizar uma discussão sobre a influência do medo na formulação da política de defesa, em especial de Israel. Apresentaremos o conceito de medo para Hobbes e a discussão de sua aplicação, para os realistas e psicólogos políticos, no que tange à relação entre os Estados. A hipótese a ser desenvolvida recai na contraposição à aplicação do conceito de medo pelo Realismo utilizando o conceito de aprendizado da Psicologia Política e a influência do aprendizado do medo para a formulação da política externa, mais especificamente na área de segurança israelense, considerando que as perseguições vividas pelo povo judeu no século XX e os conflitos travados entre Israel e outros Estados ajudaram a aumentar os efeitos do medo hobbesiano, contribuindo para a criação e a legitimação de políticas hostis na esfera da defesa. 
0 que distingue o homem de todos os outros animais, além da razão, é, para Hobbes (1983), a vontade de saber as causas. Quando outros animais deparam com algo novo, seu único interesse é se o objeto é suscetível de ajudar ou prejudicar o ambiente naquele momento. Já quando os homens veem algo novo, eles tentam descobrir a sua causa. Outros animais vivem quase que inteiramente no presente, porque pouca ou nenhuma previsão do futuro é possível. Para os homens, por outro lado, o medo se localiza não só no presente, mas no futuro também. Pelo fato de os homens serem capazes de reconhecer a dependência de um evento sobre o outro, o medo se estende, necessariamente, tanto quanto os seus pensamentos e causas (BLITS, 1989).

O homem pode entender somente o que ele faz, apenas os acontecimentos de que ele é a causa ou cuja construção ou geração encontra-se totalmente dentro de sua alçada. Ele pode saber que todo fenômeno natural é causado por algum tipo de movimento. Mesmo assim, a natureza é, em princípio, desconhecida.

Nascemos, de acordo com Hobbes (1983), com apenas alguns apetites e nenhuma aversão particular. Temos um apetite natural para a comida, mas não para tomar um sorvete ou comer uma carne assada. Todos os apetites particulares são adquiridos a partir da experiência, isto é, para testar seus efeitos sobre nós mesmos ou outros homens. Nós teríamos aversão pelas coisas que nos magoaram, mas também pelas que não sabemos se vão nos ferir ou não. Desejos pressupõem experiência; os temores, não. Podemos desejar somente o que nós acreditamos que não vai nos machucar, mas temos medo de tudo o que não sabemos se não vai nos causar dor.

Enquanto podemos desejar algo somente se nós o sabemos, nós naturalmente tememos algo precisamente porque nós não o conhecemos. 0 conhecimento é uma condição necessária para o desejo; a ignorância é uma condição suficiente para o medo. Desde que nascemos ignorantes, nascemos sem desejos em particular, mas com um medo geral de tudo. Nós nascemos com um medo que não tem nenhum objeto em particular, precisamente porque é um medo do desconhecido. Como o medo de outros homens, assim como qualquer outro medo particular, exige experiência, mesmo que apenas a experiência de introspecção, a insegurança mais radical do homem precede toda experiência e é subjacente a todos os medos específicos (BLITS, 1989). 
O medo é uma dor, e os homens naturalmente evitam a dor. Os homens tentam evitar não só o objeto do medo, mas o próprio medo. Porém, um medo sem objeto é um medo insolúvel. Ninguém pode lutar ou fugir do que ele não pode identificar ou saber para ser resolvido. 0 medo tem que corresponder a algo; ele deve ter um objeto. Assim, quando um objeto está faltando, os homens vão encontrar um imaginário, vão inventar um objeto identificável que eles possam temer. E, portanto, quando não há nada para ser visto, não há nada a acusar, mas algum poder ou agente invisível. 0 medo é, portanto, capaz de dar forma ao sem-forma. Ele também personifica os objetos que os homens criam para tornálos agentes do medo. Os homens imaginam causa pessoal, isto é, aquela que tem uma vontade ou a intenção como a sua própria, pela mesma razão que imaginam qualquer causa. 0 medo das forças desconhecidas assimila o desconhecido para o conhecido, visando entender o desconhecido em termos do familiar (BLITS, 1989).

A indeterminação do medo mostra, assim, a conexão entre o desejo natural do homem pela liberdade e sua tendência natural a se submeter à autoridade. A liberdade é a ausência de impedimentos externos, a ausência de oposição, para Hobbes (1983). 0 que importa não é o que "eu faço", mas que nada externo a mim me impeça de fazer o que eu quero fazer. A liberdade é, literalmente, em aberto. Se, então, a liberdade, como o medo, é indeterminada, é na indeterminação da força do medo que os homens contam com a autoridade. A ignorância de causas naturais em ambos impede os homens de inquirir sobre as causas das coisas.

Partindo dessa análise sobre o medo, a teoria realista em Relações Internacionais utiliza essa interpretação para fundamentar a relação entre os Estados. A principal característica do Sistema Internacional para o Realismo/Neorrealismo é a anarquia, de acordo com Hans Morgenthau (2003). Em tese, a anarquia é a ausência de um governo central que exerça um poder coercitivo nas unidades, porém, para o Realismo, esse conceito é mais amplo: anarquia é a ausência de um governo supranacional que também forneça proteção, de acordo com Joseph Grieco (1988). Dessa forma, a insegurança, gerada pelo medo, e a ausência de um Estado central propiciam um ambiente instável e predisposto ao conflito.

Assim, para o Realismo, o medo é algo igualmente distribuído no Sistema Internacional, e, sem a mudança da estrutura do sistema graças à anarquia, os Estados naturalmente praticariam o equilíbrio de poder. A questão do equilíbrio de poder é 
amplamente explorada tanto por Morgenthau (2003) quanto por Kenneth Waltz (2000). Para o primeiro, o que leva as nações a buscar o equilíbrio de poder é a manutenção ou alteração do status quo. "O equilíbrio internacional de poder representa apenas uma manifestação particular de um princípio social de ordem geral, ao qual todas as sociedades compostas de certo número de unidades autônomas devem a autonomia de suas partes componentes" (MORGENTHAU, 2003, p. 321). Podemos definir equilíbrio também como balanço, estabilidade dentro de um sistema composto de várias forças autônomas (vide anarquia).

Retomando o conceito de anarquia, ou seja, ausência de um governo central que exerça um poder coercitivo e que provenha proteção, o Sistema Internacional, portanto, segue essas determinações. Uma vez que os países não têm algo que "os proteja”, o sistema possui uma característica conhecida como self-help, termo cunhado por Kenneth Waltz (1979). Esse elemento pode ser definido como a responsabilidade dos Estados de se proteger. É a partir dessa necessidade que eles se fortalecem e se armam.

Pode-se dizer que os Estados conduzem suas políticas através da violência. Todo Estado deve estar preparado para ter que usar de violência em algum momento. 0 "estado de natureza", que, no caso, é aquele em que os Estados se encontram, é o Estado da Guerra (HOBBES apud WEFFORT, 2011). Os Estados, como as pessoas, vivem num paradoxo da liberdade e da segurança - segurança muitas vezes almejada pela realidade presente do medo hobbesiano (WALTZ, 2000).

Entretanto, o Realismo pressupõe que o medo e a insegurança possuem o mesmo efeito e o mesmo nível em todos os Estados de forma igual, mas a hipótese deste artigo é que esse efeito é diferente e o medo pode ser maior em certas sociedades do que em outras, por diversos fatores. No presente trabalho, enfocaremos um dos fatores: o aprendizado.

Jack S. Levy (1994) define aprendizagem como uma mudança de crenças (ou do grau de confiança em suas crenças) ou o desenvolvimento de novas crenças, habilidades ou procedimentos como resultado da observação e interpretação da experiência.

O aprendizado não é uma atividade passiva em que os eventos históricos geram suas próprias lições e os atores absorvem. A aprendizagem é ativa em vários aspectos. Primeiramente, ela é uma construção analítica. As pessoas interpretam a experiência 
histórica através das lentes de suas próprias suposições e visões de mundo analíticas. Assim, o medo hobbesiano pode ser intensificado, mudando o grau de como o medo está inserido na sociedade. Ao contrário do que o Realismo propõe, os diferentes quadros em que as pessoas se encontram geralmente resultam em variações na aprendizagem entre os indivíduos na mesma situação. Essa é uma hipótese de trabalho de modelos de aprendizagem, e sua validade é uma questão central para a pesquisa empírica no que diz respeito a questões específicas ou casos (LEVY, 1994).

Em segundo lugar, ainda de acordo com Levy (1994), os atores procuram ativamente a informação que eles acreditam que é necessária para uma interpretação válida da experiência histórica. Atores também realizam experimentos para "testar" seus pressupostos: implementar pequenas mudanças políticas, observar seus efeitos e aprender por tentativa e erro.

Os analistas que se concentram no aprendizado dentro das comunidades epistêmicas enfatizam a importância tanto do quadro conceitual, por meio do qual atores interpretam a experiência, quanto do processo político através do qual os especialistas tentam moldar a opinião dos líderes políticos (LEVY, 1994).

\section{O aprendizado do medo hobbesiano e a política de defesa israelense}

Dentre os diversos modelos teóricos de análise de política externa, podemos destacar o surgimento de uma série de abordagens que podem ser denominadas de middle-range (que incluem as análises de Psicologia Política, como a Teoria do Aprendizado), de acordo com Steve Smith (1986).

Esse grupo de abordagens possui como característica o nível de análise do Estado e do indivíduo, combatendo as teorias sistêmicas que tinham dominado as análises. Não só isso, mas as teorias de middle-range enfocam um conjunto muito restrito de fatores, com base no pressuposto de que a política externa poderia ser mais bem entendida examinando-se o impacto de determinados processos dentro da estrutura de tomada de decisão. As teorias de Psicologia Política têm várias vertentes diferentes: Jervis, em seu livro Perceptions and misperceptions in international politics, concentra sua análise sobre a natureza das percepções; Irving L. Janis olhou para o papel dos processos psicológicos dentro de grupos de tomada de decisão; entre outros (SMITH, 1986). Assim, 
continuaremos utilizando a Teoria do Aprendizado neste artigo para analisar a influência do medo na política externa israelense.

Além de aprender sobre as leis causais e condições iniciais, os indivíduos também aprendem a aprender. Eles se instruem sobre novas regras de decisão, heurísticas de julgamento, procedimentos e habilidades que facilitam a sua capacidade de aprender a partir da experiência subsequente (LEVY, 1989).

0 aumento da capacidade de aprendizado se reflete na reforma organizacional, para melhorar a qualidade de pesquisa e análise de informações, de forma a também aperfeiçoar a memória organizacional. Além disso, incorpora novas regras de decisão ou técnicas analíticas, passa a utilizar conhecimentos técnicos ou especialistas acadêmicos, ampliando o uso de computadores, ou desenvolvendo novas capacidades (LEVY, 1989).

A aprendizagem não deve ser equiparada com as analogias históricas. Apesar de lições de eventos-chave serem uma importante forma de aprendizagem, sobretudo tendo em conta a tendência psicológica de pessoas que passaram por eventos traumáticos, a aprendizagem também pode envolver a atualização de crenças já presentes, de forma a absorver novas habilidades ou procedimentos, ou a mudança de crenças ao longo do tempo como resultado da acumulação gradual de experiência. No caso do medo, o aprendizado intensifica esse sentimento natural do homem, de acordo com Hobbes (1983).

Essa definição levanta questões difíceis sobre o significado e a relevância dos conceitos de aprendizado organizacional ou governamental. Para Levy (1989), o argumento é que são analiticamente inviáveis o aprendizado para o nível coletivo e a suposição de que as organizações ou governos podem ser tratados como organismos que têm objetivos, crenças, e não memórias. Entretanto, as organizações são compostas de pessoas, e essas pessoas aprendem, influenciando o comportamento das organizações.

Mesmo assim, essa perspectiva é amplamente aceita na literatura sobre aprendizagem organizacional. Esta não é sinônimo de aprendizagem individual. Assim, organizações não literalmente aprendem. Não há aprendizagem organizacional sem a individual, sendo que a primeira é uma metáfora (LEVY, 1989).

Entretanto, para Levy (1989), nem toda mudança organizacional deriva de aprendizagem. 0 processo envolve aprendizado somente se inclui mudança cognitiva 
individual e somente se os indivíduos, a partir da experiência, incorporam nas práticas organizacionais e nos procedimentos o fruto dessa aprendizagem. Assim, a aprendizagem organizacional envolve um processo de vários estágios em que experiências levam à aprendizagem individual, o que induz à ação individual para mudar procedimentos organizacionais, o que, por fim, leva a uma mudança em comportamento organizacional.

Assim, analisaremos a teoria de Daniel Bar-Tal (2001) de que o medo se sobrepõe à esperança em Estados que possuem conflitos intermitentes enraizados em sua história, como, por exemplo, Israel, juntamente com o aprendizado do medo hobbesiano desenvolvido até aqui.

Para Bar-Tal (2001), o medo é uma reação psicológica fundamental do ser humano, assim como para Hobbes (1983), consequentemente, desempenhando um papel importante na determinação do comportamento humano. Em essência, as emoções são um fenômeno multifacetado de sentimentos subjetivos acompanhados de respostas fisiológicas, cognitivas e comportamentais. Em outras palavras, as emoções servem como mediadoras para os processos de julgamento, avaliação e tomada de decisões.

Dessa forma, o conflito árabe-israelense no Oriente Médio é derivado de um conflito sobre um território contestado conhecido como Palestina, o qual, atualmente, dois movimentos reivindicam: o movimento de libertação da palestina e o sionismo. ${ }^{2}$

Ao longo das décadas, o conflito foi adquirindo um caráter insolúvel, culminando em conflitos interestatais de grande escala desde 1948 (Primeira Guerra ÁrabeIsraelense) até 1973 (Guerra do Yom Kippur). Esses conflitos tiveram um papel importante como forma de enraizar o medo na sociedade israelense, levando em consideração a teoria do aprendizado discutida na seção anterior. As experiências de guerras contínuas acabaram por gerar, na sociedade, um aprendizado de insegurança e de medo, com o medo da morte violenta, de Hobbes, ocupando um lugar central no debate político do Estado.

Os cidadãos israelenses se sentiam ameaçados não só como um coletivo em um Estado, mas principalmente como indivíduos: muitos deles participaram das ações militares e se tornaram vítimas da violência, direta ou indiretamente (BAR-TAL, 2001).

\footnotetext{
${ }^{2}$ Movimento político-filosófico defensor da autodeterminação do povo judeu, com Israel como o Estado nacional do povo judaico.
} 
Assim, o aprendizado se dá no nível do indivíduo, mas, no caso dos conflitos em nível estatal, esse aprendizado se estende para mais indivíduos moldando a sociedade e espalhando o sentimento de medo pelas mais diversas esferas.

Devemos também ressaltar que não foram só as guerras que possuíram um impacto importante na construção da narrativa israelense. A trajetória do povo judeu também tem um papel determinante. Bar-Tal (2001) cita a perseguição dos judeus por não judeus, a sensação de cerco e aprisionamento na diáspora e as ameaças e perigos que os judeus enfrentaram, os quais, somados às guerras pós-criação do Estado, acabaram por fomentar o sentimento de medo. Assim, visto como um clímax simbólico que tende a representar todo o sofrimento judeu ao longo da história, o Holocausto ocupa posição de destaque no aprendizado do medo hobbesiano pelos israelenses. Muitas das obras sobre o Holocausto contêm descrições realistas-naturalistas de sofrimento, agonia e morte, o que implica medo, impotência e desesperança.

A preocupação com o conflito árabe-israelense é não só determinante na vida pública e política de Israel, mas também bastante presente na literatura, o que reforça o discurso do medo hobbesiano. Os árabes frequentemente são retratados como assustadores, cruéis, desumanos e decididos a destruir e matar. Da mesma forma, retratos negativos e ameaçadores de árabes também podem ser encontrados na literatura infantil israelense. Bar-Tal (2001) cita estudos que analisaram a imagem do árabe em livros infantis da década de 1950 até o início de 1980. Os árabes foram consistentemente desumanizados como uma entidade ameaçadora, começando com a descrição de sua aparência externa e terminando com caracterizações de cunho psicológico e frequentemente plano.

Os efeitos do aprendizado do medo na sociedade israelense têm um papel importante na formulação da política externa de segurança e, assim, na forma como Israel se posiciona em relação aos outros Estados, principalmente os da região.

De especial interesse para este artigo são os estudos que investigaram os efeitos do medo na sociedade israelense. De acordo com Bar-Tal (2001), em geral, os resultados indicam uma relação muito robusta entre percepção de ameaças e posições conciliatórias em relação à solução dos conflitos. Nas respostas às pesquisas, os judeus israelenses, em sua maioria, acreditam que estão sozinhos em um mundo hostil. Os últimos resultados foram replicados no período entre 1996 e 1999, com amostras nacionais de judeus 
israelenses mostrando uma posição conciliatória em direção à resolução pacífica do conflito, a qual está relacionada com uma esperança para a paz e uma avaliação da eclosão da guerra como improvável.

Nas sociedades que foram ou estão envolvidas em conflitos intermitentes, o domínio de uma orientação ao medo coletivo não é a exceção, mas a regra. A orientação emocional coletiva do medo é funcional durante os anos de conflito intermitente, mas, quando as sociedades envolvidas nesses conflitos começam um processo de paz, essa orientação emocional torna-se um importante obstáculo psicológico para a pacificação no que tange à política externa.

No caso de Israel, a visita de Sadat $^{3}$ ao país em 1977, que foi seguida pela assinatura do acordo de paz entre Israel e Egito, em 1979, deu início a mudanças na natureza intratável do conflito árabe-israelense. O longo caminho em direção à paz contou, também, com os acordos de Oslo com a Organização para a Libertação da Palestina (OLP), em 1993, com o tratado de paz entre Israel e Jordânia em 1994, com as negociações com a Síria, entre outros (BAR-TAL, 2001). Porém, o aprendizado do medo e os efeitos coletivos desse aprendizado, refletindo-se em nível institucional e pautando a política externa, servem como um atraso para o progresso do processo de paz. A contínua erupção de violência, principalmente contra a facção do Hamas na Faixa de Gaza, evoca profundos temores da sociedade israelense e a faz regredir consideravelmente em sua esperança para a paz. 0 medo continua presente na sociedade e acaba, muitas vezes, sendo utilizado como forma de legitimação de políticas pelo governo, como, por exemplo, a sucessiva expansão dos assentamentos israelenses nos territórios ocupados da Cisjordânia.

A desconexão do domínio do medo e o compromisso com uma esperança para a paz são necessários se as sociedades querem buscar o fim de conflitos persistentes, limitando as crenças que alimentam a continuação desses conflitos e formando novas crenças funcionais para a reconciliação.

O medo hobbesiano, como tratado na primeira parte deste artigo, se refere ao desconhecido, ao que não se sabe se causará sofrimento ou não. A psicologia da esperança envolve processos mentais mais elevados de visão e imaginação, a definição de objetivos e a consideração de alternativas, diferentemente do medo, que, de acordo com Hobbes

\footnotetext{
${ }^{3}$ Anwar Al Sadat foi presidente do Egito de 1970 a 1981 e ganhou o Prêmio Nobel da Paz em 1978 pela assinatura do acordo de paz com Israel.
} 
(1983), seria inato ao homem. Para se desvincular do medo, esses processos têm de superar o surgimento espontâneo dele. Essa é uma tarefa muito difícil, haja vista o fato de que, mesmo durante um processo de paz num conflito, o medo ainda continue a existir e ainda tenha reflexos violentos, como em ataques terroristas contra civis, retórica agressiva, agitação e adoção de políticas hostis que, muitas vezes, são fruto do processo de aprendizado e enraizamento do medo na sociedade, elevado ao nível das instituições.

\section{Conclusão}

Os efeitos do medo na sociedade israelense estariam distribuídos de forma mais exacerbada do que em sociedades que não teriam experienciado a mesma história de perseguição e conflitos. 0 medo hobbesiano seria inato ao ser humano, mas ele poderia ser nivelado de forma diferente no Sistema Internacional. Dessa forma, os efeitos do medo, quando mais elevados, como em Israel, resultariam em políticas mais agressivas como justificativa da defesa, sendo legitimadas pela população por meio da construção de narrativas.

Os perigos e as ameaças ainda estão muito vivos no imaginário dos israelenses. Atos hostis e agressivos não vão cessar de uma vez simplesmente, mas, de acordo com Bar-Tal (2001), tendem a diminuir e a continuar nesse processo por anos e até mesmo aumentar ocasionalmente, como picos em um gráfico. Em tal realidade, em que as memórias coletivas do conflito, utilizadas como base do aprendizado em uma população, são salientes com outras memórias coletivas e, muitas vezes, com o discurso do próprio governo, provocando o medo, como o Holocausto e outras perseguições a judeus ao longo da história, a orientação do medo coletivo continua a ser uma força poderosa na psique dessas sociedades.

Esse medo acaba por trazer à tona as crenças e ideias sobre o passado de ameaças e perigos, desencadeando certas reações, principalmente na política. 0 resultado é a desconfiança, a dependência de pressupostos e as concepções passadas, o que alimenta a continuação do conflito.

Assim, o medo, de acordo com Hobbes (1983), seria inerente a todos os homens, mas não distribuído igualmente e no mesmo nível por todo o Sistema Internacional, como propõe o Realismo. 0 medo acaba por se comportar de diferentes formas graças a diversos 
fatores que tendem a intensificar ou reduzir seus efeitos nas sociedades e, por sua vez, no comportamento dos Estados. Neste artigo abordamos o aprendizado em política externa que possui um efeito de baixo para cima, no qual os efeitos do medo são sentidos na sociedade e se elevam ao nível institucional, que, junto com o debate público, influencia a formulação da política externa.

Dessa forma, neste trabalho, ainda que limitadamente, começamos uma pesquisa sobre os efeitos do medo na sociedade israelense e, principalmente, na política externa de segurança. Futuramente, é necessária uma pesquisa do processo decisório propriamente dito na política externa para observar os efeitos do medo nessa esfera, se desdobrando da sociedade para níveis institucionais. Entretanto, o que podemos observar com esta pesquisa preliminar é que o aprendizado do medo ainda pode ser considerado como doutrina na sociedade israelense, presente na educação formal de seus cidadãos desde a tenra idade e possuindo efeitos duradouros para o debate político como um todo.

\section{Referências Bibliográficas}

BAR-TAL, Daniel. Why Does Fear Override Hope in Societies Engulfed by Intractable Conflict, as It Does in the Israeli Society? Political Psychology, Vol. 22, No. 3, 2001.

BLITS, Jon H. Hobbesian Fear. Political Theory, Vol. 17, No. 3, pp. 417-431, Aug., 1989.

GRIECO, Joseph. Anarchy and the Limits of Cooperation: A Realist Critique of the Newest Liberal Institutionalism. International Organization 42 (3):485-507. 1988.

HOBBES, Thomas. O Leviatã. 3a ed. São Paulo: Abril Cultural, 1983.

JERVIS, Robert. Perceptions and Misperceptions in International Politics. Princeton: Princeton University Press, 1976. 464 p.

LEVY, Jack S. Learning and foreign policy: sweeping a conceptual minefield. International Organization, v. 48, n. 2, mar. 1994. p. 279-312.

MCDERMOTT, Rose. Political psychology in international relations. Ann Arbor: The University Of Michigan Press, 2004.

MORGENTHAU, Hans. A Política Entre as Nações. Universidade de Brasília. Brasília, 2003.

ROUSSEAU, Jean Jacques. Do Contrato Social - Col. Saraiva de Bolso. Editora Saraiva, 2011.

SMITH, Steve. Theories of Foreign Policy: An Historical Overview. Review of International Studies, v. 12, n. 1, 1986. p. 13-29.

WALTZ, Kenneth. Structural Realism after the Cold War. International Security, v. 25, n.1, 2000, p. 5-41.

WALTZ, Kenneth N.. Theory of International Politics. Long Grove: Waveland Press, 1979. WEFFORT, Francisco. Os clássicos da política. Vol. 1. Editora Ática, 2011. 